\title{
COMUNICAÇÃO
}

\section{ENRAIZAMENTO DE ESTACAS HERBÁCEAS DE GUARANAZEIRO EM DIFERENTES SUBSTRATOS}

\author{
Survival rate of guarana herbaceous cuttings in different substrates \\ Murilo Rodrigues de Arruda ${ }^{1}$, José Clério Rezende Pereira ${ }^{1}$, Adônis Moreira ${ }^{1}$, \\ Wenceslau Geraldes Teixeira ${ }^{1}$
}

\begin{abstract}
RESUMO
A utilização de sementes na propagação do guaranazeiro propicia alta variabilidade na produtividade e suscetibilidade a doenças, por isto, no Amazonas, recomenda-se a propagação do guaranazeiro por meio do enraizamento de estacas herbáceas de materiais selecionados. Objetivou-se com este trabalho, avaliar o enraizamento, em tubetes, de estacas herbáceas de doze clones de guaranazeiro submetidas a três diferentes substratos. Os clones avaliados foram o BRS 300, BRS 871, BRS 372, BRS 648, BRS 189, BRS 505, BRS 610, BRS 612, BRS 850, BRS 882, BRS 608, BRS 611. Os substratos testados foram uma mistura com base em volume de $50 \%$ de solo $+50 \%$ de esterco de galinha $(\mathrm{v} / \mathrm{v}) ; 50 \%$ de esterco de galinha $+50 \%$ de carvão moído passado em peneira de $10 \mathrm{~mm}(\mathrm{v} / \mathrm{v})$ e substrato comercial para hortaliças $\left(\right.$ Plantmax $\left.^{\circledR}\right)$. O substrato comercial e o esterco de galinha + carvão proporcionaram a maior porcentagem de enraizamento das estacas. O clone BRS Amazonas obteve o maior percentual de enraizamento $(88,2 \%)$, enquanto o clone BRS 372, o menor (15\%).
\end{abstract}

Termos para indexação: Paullinia cupana, carvão vegetal moído, esterco de galinha, Plantmax ${ }^{\circledR}$, propagação.

\section{ABSTRACT}

The propagation of the guarana plants using seeds is nowadays not recommended because the high variability in the productivity and susceptibility to diseases. The cuttings propagation of a select guarana plant clones is recommended for Amazonas State. The objective of this study was to evaluate the survival rate of cuttings of twelve clones of guaraná in three substrates with three replicates. The evaluated clones were: BRS 300, BRS 871, BRS 372, BRS 648, BRS 189, BRS 505, BRS 610, BRS 612, BRS 850, BRS 882 , BRS 608 , BRS 611 . The growing media tested were $50 \%$ of soil $+50 \%$ of chicken manure (v/v); $50 \%$ chicken manure $+50 \%$ sieved powdered charcoal (v/v) and a comercial growing media for vegetables (Plantmax ${ }^{\circledR}$ ). The comercial growing media and the misture of chicken manure + sieved powdered charcoal substrate produced the higher cuttings survival rate. The clone BRS Amazonas showed the highest percentage of survival $(88.2 \%)$ and clone BRS 372 the lowest (15\%).

Index terms: Paullinia cupana, charcoal, chicken manure, Plantmax ${ }^{\circledast}$, growing media.

(Recebido para publicação em 15 de julho de 2005 e aprovado em 22 de agosto de 2006)

O guaranazeiro (Paullinia cupana var. sorbilis (MART.) DUCKE) pode constituir uma fonte de renda alternativa para populações amazônidas interioranas e, desta forma contribuir para a redução do êxodo rural.

Não obstante o interesse por parte dessas populações pela cultura, a sua produtividade é incipiente devido à elevada heterogeneidade do material cultivado originado de sementes, como consequiência da alogamia e a existência de guaranazais antigos e decadentes (CORRÊA, 1984), fato verificado ainda hoje. Além disso, as mudas obtidas de sementes têm elevada probabilidade de serem severamente atacadas pela antracnose, doença causada por Colletotrichum guaranícola que contribui para alta mortalidade das plantas, reduzindo consideravelmente os estandes (ARAÚJO et al., 2002).
Segundo o Instituto Brasileiro de Geografia e Estatística, IBGE (2003), a produtividade do Município de Maués, maior produtor do Amazonas, foi de $151 \mathrm{~kg} \mathrm{ha}^{-1} \mathrm{de}$ sementes secas de guaraná, o que representa $25 \%$ da produção esperada quando se cultivam os clones BRS 871 ou BRS 300, por exemplo, os quais produzem, em média, 1,5 kg planta $^{-1}$ ou $600 \mathrm{~kg} \mathrm{ha}^{-1}$ (ATROCH, 2001).

A utilização de sementes na propagação do guaranazeiro, além de propiciar alta variabilidade com relação aos caracteres produtividade e suscetibilidade à antracnose, é onerosa, pois apresenta rápida perda do poder germinativo, uma vez que, segundo Carvalho et al. (1982), não suportam desidratação acentuada. Dessa forma, a propagação do guaranazeiro tem sido recomendada basicamente por meio do enraizamento de estacas

1Pesquisador Embrapa Amazônia Ocidental - Cx. P. 319 - 69011-970 - Manaus, AM - murilo@cpaa.embrapa.br; adonis@cpaa.embrapa.br; lau@cpaa.embrapa.br 
herbáceas (EMBRAPA, 1998) no Amazonas. Entretanto, como mencionado por Atroch et al. (2002), existe um forte componente genético com relação à capacidade e/ou habilidade para o enraizamento entre os diferentes clones de guaranazeiro, o que pode inviabilizar a produção de um material em larga escala, mesmo que tenha potencial produtivo.

Por não se tratar de um problema exclusivo do guaranazeiro, vários substratos comerciais e vermiculita têm sido estudados na produção de mudas de diferentes culturas (SALVADOR \& MOREIRA, 1999; SANTOS et al., 2004; SILVA et al., 2001). Em geral, os maiores ganhos na produção de mudas e/ou enraizamento de estacas têm sido obtidos com a utilização de substratos constituídos por restos vegetais ou compostos orgânicos, tais como casca de pinus associada a vermiculita, bagaço de cana-deaçúcar, torta de filtro, vermicomposto, casca de coco, entre outros (BEZERRA \& ROSA, 2002; MOURÃO FILHO et al., 1998; SALVADOR \& MOREIRA, 1999). Esses substratos apresentam como características em comum, baixos níveis de metais pesados e elevada porosidade, o que possibilita o escoamento rápido da água de irrigação ou de nebulização, impedindo que as raízes e/ou radicelas sejam submetidas à baixa oxigenação.

Sistemas radiculares submetidos à hipoxia sofrem modificações fisiológicas e anatômicas nas células do parênquima, predispondo-as ao ataque de fitopatógenos e reduzindo a seletividade da membrana citoplasmática, tornando a planta suscetível à absorção passiva de metais pesados que também provocam necroses nas raízes e radicelas (AGUILAR et al., 2000).

Desta forma, este trabalho teve como objetivo determinar a porcentagem de enraizamento de estacas de clones de guaranazeiros recomendados para as condições edafoclimáticas do Amazonas, em três diferentes substratos.

O experimento foi conduzido no viveiro de produção de mudas do Campo Experimental da Embrapa Amazônia Ocidental, localizado no km 29 da Rodovia AM010 , nas coordenadas $3^{\circ} 8^{\prime} \mathrm{S}$ e $59^{\circ} 52^{\prime} \mathrm{W}$, Município de Manaus (AM). As estacas foram coletadas, plantadas e conduzidas de acordo com as técnicas recomendadas (EMBRAPA, 1998).

Avaliaram-se os seguintes substratos: solo coletado no Campo Experimental da Embrapa Amazônia Ocidental em Manaus (Latossolo Amarelo, textura muito argilosa corrigido e fertilizado com $2.500 \mathrm{~g}$ e $500 \mathrm{~g}$ de calcário dolomítico e superfosfato triplo, respectivamente, por $\mathrm{m}^{3}$ de solo) misturado com esterco de galinha, na proporção de 1:1 com base volumétrica (v/v); esterco de galinha misturado com carvão vegetal, na proporção de $1: 1(v / v)$ e substrato comercial Plantmax ${ }^{\circledR}$ hortaliças.
Durante a produção e transporte do carvão vegetal, parte do material se fragmenta em pedaços pequenos que não são comercializados. Assim este tipo de material é facilmente encontrado na região, a preços baixos. Por isso decidiu-se testar este subproduto da produção de carvão, passado em peneira de $10 \mathrm{~mm}$ para homogeneização do material, como substrato.

Utilizaram-se estacas herbáceas dos clones de guaranazeiro provenientes da Embrapa Amazônia Ocidental: BRS 300, BRS 871, BRS CG372, BRS CG648, BRS CG189, BRS CG505, BRS CG610, BRS CG612, BRS CG850, BRS CG882, BRS CG608, BRS CG611.

Foram coletadas estacas herbáceas lançadas no ano, em abril de 2003. Logo após a coleta, a parte basal das estacas foi colocada em contato por alguns segundos com o fitormônio ácido indol-3-butírico (AIB) na concentração de $2.000 \mathrm{mg} \mathrm{L}^{-1}$, misturado com talco inerte, para estimular o enraizamento (ATROCH et al., 2002; EMBRAPA, 1998), e plantadas em tubetes de $250 \mathrm{~cm}^{3}$ de volume.

Cinco meses após o plantio, quantificou-se o número de estacas vivas, considerando-se enraizada ou viável aquela possuísse ao menos um par de folhas completamente desenvolvido.

Foi determinado também, em amostras coletadas com cilindro nos diferentes substratos, a densidade e a umidade retida pelos substratos após serem equilibrados em mesa de tensão nas tensões $0,10,30$ e $60 \mathrm{~cm}$ de coluna de água. Com base nos resultados da água retida foi determinada a porosidade total, considerada como a porosidade da amostra saturada. A determinação da macro e microporosidade foi feita considerando a água retida após as amostras serem submetidas à tensão de $60 \mathrm{~cm}$ como retida nos microporos. Detalhes metodológicos utilizados nestas determinações são descritos em Embrapa (1997).

$\mathrm{O}$ delineamento foi inteiramente casualizado, em esquema fatorial $3 \times 12$ (três substratos e doze clones), perfazendo 36 tratamentos, com três repetições. Cada parcela possuía 18 estacas totalizando 54 estacas por tratamento. Os dados obtidos foram transformados para " $\mathrm{x}+0,5$, e para a análise estatística foi utilizado o programa SANEST. Os tratamentos que apresentaram significância estatística na ANOVA, tiveram suas médias comparadas pelo teste de Duncan a 5\% de probabilidade (FERREIRA, 1996).

Na Tabela 1 está a composição química dos substratos avaliados. Nota-se em todos eles uma elevada concentração de nutrientes, com até 4560 e $9380 \mathrm{mg} \mathrm{dm}^{-3}$ de fósforo e potássio, respectivamente, e em especial naqueles em que foi utilizado o esterco de galinha, que apresentou além disto, sódio em demasia. Desta forma, a proporção do esterco de galinha no substrato deverá ser revista . 
Não foi possível quantificar a produção de raízes, pois após os cinco meses de avaliação, a massa de raízes formadas era ainda muito pequena e frágil, se perdendo com o substrato, quando manipuladas.

Pela análise de variância dos tratamentos, notou-se diferenças significativas entre os clones, entre os substratos e interação clone x substrato (Tabela 2). Considerando-se as médias de sobrevivência das estacas entre os clones de guaranazeiro, independente do substrato, percebe-se que o clone BRS 300 foi o que apresentou as maiores taxas de pegamento, apesar de não diferir estatisticamente dos clones BRS 610 e BRS 871 (Tabela 3).

O menor índice de sobrevivência foi o do clone BRS 372, com apenas 15\% das estacas viáveis. Além desse, os clones BRS 612, 850, 189, 611, 505, 608 e 882 obtiveram taxa de sobrevivência inferior a $60 \%$, tornando sua multiplicação onerosa, por ocuparem grandes áreas em viveiros comerciais para uma baixa produtividade e exigirem a implantação e manutenção de elevado número de matrizes no campo para coleta de estacas.

Corrêa \& Stolberg (1981) observaram que o percentual de enraizamento de estacas de guaranazeiro retiradas de diferentes plantas variou de $14,3 \%$ a $100 \%$. Atroch et al. (2002) verificaram que o índice de enraizamento de onze clones de guaranazeiro variou de $16,6 \%$ a $85,2 \%$ e que existe variabilidade genética para o caráter porcentagem de enraizamento. Segundo esses autores, os clones BRS 300 e 505 obtiveram porcentagem de enraizamento de $81,4 \%$ e $37,2 \%$, respectivamente, valores semelhantes aos encontrados na Tabela 3 . O clone BRS 611, no entanto, atingiu $67,8 \%$ de índice de enraizamento contra 41,4\%, sugerindo ainda que alguns clones podem ser mais suscetíveis às condições edafoclimáticas e de manejo no viveiro.

$\mathrm{Na}$ Tabela 4, constam os dados do índice de sobrevivência das estacas de acordo com o substrato. $\mathrm{O}$ substrato comercial e o esterco de galinha + carvão proporcionaram os melhores resultados, com $55,9 \%$ e $49,3 \%$ de índice médio de pegamento dentro dos clones. O substrato esterco de galinha + solo se mostrou pouco eficiente, com 37,9\% de sobrevivência de estacas. Mourão Filho et al. (1998) concluíram que a composição do substrato influencia diretamente o desenvolvimento de porta-enxertos de citros e que o uso exclusivo de solo como substrato apresentou resultados inferiores quando comparado com o uso de solo misturado com outros materiais, como esterco bovino.

No caso das mudas de guaranazeiro, nota-se que as plantas são sensíveis ao excesso de água, em qualquer estádio do enraizamento, causando mortalidade, se houver encharcamento. Os solos utilizados como substratos no Amazonas, além de serem pobres em nutrientes (MOREIRA \& MALAVOLTA, 2002), são, na maioria das vezes, argilosos (CORRÊA, 1981), dificultando a drenagem da água da irrigação, que deve ser constante no viveiro, pelo menos nos quatro primeiros meses após o plantio das estacas, seja em tubetes ou em sacos plásticos, para não afetar negativamente o índice de pegamento, em consequiência da desidratação das mudas. No caso da mistura do solo + esterco de galinha, obteve-se um substrato denso, que se encharcava com facilidade, e assim permanecia por horas, podendo ter induzido as estacas à morte por falta de oxigenação dos tecidos que dariam origem ao sistema radicular.

TABELA 1 - Composição química dos substratos utilizados para o enraizamento de estacas de guaranazeiro.

\begin{tabular}{|c|c|c|c|c|c|c|c|c|c|}
\hline Substrato & pH & $\begin{array}{c}\text { MO } \\
\mathrm{g} \mathrm{kg}^{-1}\end{array}$ & \multicolumn{3}{|c|}{$\mathrm{mg} \mathrm{dm}^{-3}$} & \multicolumn{3}{|c|}{$\mathrm{Cmol}_{\mathrm{c}} \mathrm{dm}^{-3}$} & $\mathbf{H}+\mathbf{A l}$ \\
\hline Plantmax $^{\circledR}$ & 4,8 & 215,0 & 825 & 660 & 45 & 14,4 & 5,2 & 0,1 & 7,1 \\
\hline Solo + esterco & 7,7 & 161,5 & 4325 & 8960 & 1180 & 6,0 & 4,1 & 0,0 & 0,4 \\
\hline Carvão + esterco & 8,5 & 148,3 & 4560 & 9380 & 1360 & 2,8 & 2,4 & 0,0 & 0,0 \\
\hline
\end{tabular}

TABELA 2 - Análise de variância para o índice de sobrevivência de 12 clones de guaranazeiro plantados em três diferentes substratos.

\begin{tabular}{lccccc}
\hline \multicolumn{1}{c}{ Causas da variação } & G.L. & S.Q. & Q.M. & Valor de F & Probabilidade > F \\
\hline Substrato & 2 & 31,92 & 15,96 & 16,77 & 0,00002 \\
Clone & 11 & 326,12 & 15,96 & 16,77 & 0,00002 \\
Clone $*$ Substrato & 22 & 46,89 & 2,13 & 2,24 & 0,00576 \\
Resíduo & 72 & 68,51 & 0,95 & - & - \\
\hline Total & 107 & 473,45 & - & - & - \\
\hline
\end{tabular}

Ciênc. agrotec., Lavras, v. 31, n.1, p. 236-241, jan./fev., 2007 
TABELA 3 - Médias originais e médias transformadas da porcentagem de enraizamento de estacas de 12 clones de guaranazeiro, cinco meses após o plantio.

\begin{tabular}{ccc}
\hline Clone & Médias Originais & Médias Transformadas \\
& $\mathbf{\%}$ & $\sqrt{\mathbf{x}+\mathbf{0 , 5}}$ \\
\hline BRS - 300 & 88,1 & $9,4 \mathrm{a}$ \\
BRS -610 & 84,9 & $9,2 \mathrm{ab}$ \\
BRS -871 & 75,7 & $8,7 \mathrm{ab}$ \\
BRS -648 & 69,0 & $8,3 \mathrm{~b}$ \\
BRS -612 & 53,6 & $7,3 \mathrm{c}$ \\
BRS -850 & 52,8 & $7,3 \mathrm{c}$ \\
BRS -189 & 47,8 & $6,9 \mathrm{c}$ \\
BRS -611 & 41,4 & $6,4 \mathrm{c}$ \\
BRS -505 & 27,3 & $5,2 \mathrm{~d}$ \\
BRS -608 & 26,2 & $5,1 \mathrm{~d}$ \\
BRS -882 & 23,3 & $4,9 \mathrm{~d}$ \\
BRS -372 & 15,0 & $3,9 \mathrm{e}$ \\
\hline
\end{tabular}

Letras distintas na mesma coluna indicam que houve diferença significativa entre os tratamentos pelo teste de Duncan a $5 \%$ de probabilidade.

TABELA 4-Médias originais e médias transformadas para $\sqrt{ } x+0,5$ da porcentagem de sobrevivência de estacas de 12 clones de guaranazeiro, cinco meses após o plantio em três substratos.

\begin{tabular}{lcc}
\multicolumn{1}{c}{ Substrato } & Médias Originais & Médias Transformadas \\
& $\boldsymbol{\%}$ & $\sqrt{\mathbf{x}+\mathbf{0 , 5}}$ \\
\hline Plantmax & 55,9 & $7,50 \mathrm{a}$ \\
Esterco de galinha + carvão & 49,3 & $7,06 \mathrm{a}$ \\
Esterco de galinha + solo & 37,9 & $6,20 \mathrm{ab}$ \\
\hline
\end{tabular}

Letras distintas na mesma coluna indicam diferença significativa entre os tratamentos pelo teste de Duncan a 5\% de probabilidade.

Pela Tabela 5, observa-se que não houve interação significativa substrato x clones para os clones BRS 648, 300, 610, 648 e 611, ou seja, estes materiais independem do substrato utilizado para seu enraizamento. Por outro lado, o clone BRS 612 mostrou elevada influência do substrato em seu enraizamento, apresentando melhor desempenho $(75,7 \%)$ quando utilizado o substrato comercial. Os clones BRS 850, 189, 505, 608, 882, e 372, apresentaram também influência do tipo de substrato em seu enraizamento, e no caso de propagação destes materiais, não se deve utilizar o substrato esterco de galinha + solo, que teve os menores índices de pegamento.
A análise física dos substratos (Tabela 6) demonstrou que o plantmax e esterco de galinha + carvão possuem maior porcentagem de porosidade total e de macroporos, em relação ao solo + esterco de galinha, além de apresentarem maior densidade e umidade volumétrica, propiciando melhor equilíbrio aeração/teor de umidade no substrato. O substrato solo + esterco de galinha apresentou significativamente, a menor proporção de macroporos, que garantem uma boa aeração para o desenvolvimento das raízes, e maior porcentagem de microporos, criando um ambiente mais propício ao encharcamento. 
TABELA 5 - Porcentagem de enraizamento de estacas de 12 clones de guaranazeiro, cinco meses após o plantio, de acordo com o substrato utilizado.

\begin{tabular}{cccc}
\hline Substrato Clone & Substrato Comercial & Esterco + Carvão & Esterco + Solo \\
\hline BRS 300 & $85,0 \mathrm{a}$ & $88,7 \mathrm{a}$ & $90,6 \mathrm{a}$ \\
BRS 610 & $90,6 \mathrm{a}$ & $79,5 \mathrm{a}$ & $84,9 \mathrm{a}$ \\
BRS 871 & $71,9 \mathrm{a}$ & $75,9 \mathrm{a}$ & $79,6 \mathrm{a}$ \\
BRS 648 & $67,6 \mathrm{a}$ & $65,6 \mathrm{a}$ & $73,9 \mathrm{a}$ \\
BRS 612 & $75,7 \mathrm{a}$ & $44,4 \mathrm{~b}$ & $43,7 \mathrm{~b}$ \\
BRS 850 & $61,1 \mathrm{a}$ & $63,8 \mathrm{a}$ & $35,9 \mathrm{~b}$ \\
BRS 189 & $58,3 \mathrm{a}$ & $68,4 \mathrm{a}$ & $23,4 \mathrm{~b}$ \\
BRS 611 & $43,3 \mathrm{a}$ & $42,5 \mathrm{a}$ & $38,5 \mathrm{a}$ \\
BRS 505 & $38,7 \mathrm{a}$ & $25,6 \mathrm{ab}$ & $19,3 \mathrm{~b}$ \\
BRS 608 & $46,7 \mathrm{a}$ & $22,0 \mathrm{~b}$ & $14,7 \mathrm{~b}$ \\
BRS 882 & $38,5 \mathrm{a}$ & $24,5 \mathrm{a}$ & $11,1 \mathrm{~b}$ \\
BRS 372 & $18,2 \mathrm{a}$ & $24,6 \mathrm{a}$ & $5,6 \mathrm{~b}$ \\
\hline
\end{tabular}

Letras distintas na mesma linha indicam diferença significativa entre os tratamentos pelo teste de Duncan a 5\% de probabilidade.

TABELA 6 - Características físico-hídricas dos substratos solo + esterco de galinha ( $1: 1 ; \mathrm{v} / \mathrm{v})$, carvão vegetal + esterco de galinha $(1: 1 ; \mathrm{v} / \mathrm{v})$ e plantmax ${ }^{\circledast}$.

\begin{tabular}{|c|c|c|c|c|c|c|c|}
\hline \multirow[t]{2}{*}{ Substrato } & \multirow{2}{*}{$\begin{array}{l}\text { Porosidade } \\
\text { total }\end{array}$} & \multirow[t]{2}{*}{ Macroporos } & \multirow[t]{2}{*}{ Microporos } & \multirow[t]{2}{*}{ Densidade } & \multicolumn{3}{|c|}{$\begin{array}{l}\text { Umidade volumétrica em } \\
\text { diferentes tensões }\end{array}$} \\
\hline & & & & & $10 \mathrm{~cm}$ & $30 \mathrm{~cm}$ & $60 \mathrm{~cm}$ \\
\hline & & $\%$ & & $\mathrm{~g} \mathrm{~cm}^{-3}$ & & $\%$ & \\
\hline $\begin{array}{l}\text { Solo + esterco } \\
\text { de galinha }(\mathrm{v} / \mathrm{v})\end{array}$ & $60,9 a$ & $24,7 \mathrm{a}$ & $36,2 a$ & $0,52 \mathrm{a}$ & $59,1 \mathrm{~B}$ & $59,1 \mathrm{~B}$ & $57,1 \mathrm{~B}$ \\
\hline $\begin{array}{l}\text { Carvão + esterco } \\
\text { de galinha (v/v) }\end{array}$ & $72,0 \mathrm{~b}$ & $35,0 \mathrm{~b}$ & $36,9 a$ & $0,39 b$ & $69,6 \mathrm{~A}$ & $68,6 \mathrm{~A}$ & $67,6 \mathrm{~A}$ \\
\hline Plantmax & $71,5 \mathrm{~b}$ & $36,7 \mathrm{~b}$ & $34,8 \mathrm{a}$ & $0,27 \mathrm{c}$ & $70,1 \mathrm{~A}$ & $69,1 \mathrm{~A}$ & $68,1 \mathrm{~A}$ \\
\hline
\end{tabular}

Letras minúsculas iguais, na mesma coluna, não diferem estatisticamente entre si pelo teste de Tukey a $1 \%$ de probabilidade; Letras maiúsculas iguais, na mesma linha, não diferem estatisticamente entre si pelo teste de Tukey a $1 \%$ de probabilidade.

Os resultados obtidos neste trabalho corroboram os alcançados por Atroch et al. (2002), com relação a haver forte efeito do componente genético e não obstante, mostraram grande efeito detrimental no pegamento de clones com reduzida habilidade para enraizamento.

Outrossim, sugere a necessidade de avaliar novos substratos preocupando-se com a capacidade de retenção e porosidade, de forma a permitir níveis ótimos de umidade e de aeração do substrato e, em adição, prevenir a compactação do substrato em benefício da emissão e crescimento de raiz e radicelas, principalmente para os clones de guaranazeiro que apresentam baixa capacidade de enraizamento. 
Assim, podemos concluir que o substrato comercial e o esterco de galinha + carvão proporcionam a maior porcentagem de enraizamento, com $55,9 \%$ e $49,3 \%$, respectivamente, sendo que o clone BRS 300 obteve o maior porcentual de enraizamento $(88,1 \%)$, enquanto o clone BRS 372, o menor (15\%).

\section{REFERÊNCIAS BIBLIOGRÁFICAS}

AGUILAR, E. A.; TURNER, D. W.; SIVASITHAMPARAM, K. Mecanismos propuestos acerca de la predisposición de los bananos Cavendish al marchitamiento por Fusarium durante la hipoxia. Infomusa, [S.1.], v. 9, n. 2, p. 9-13, 2000.

ARAúJO, J. C. A. et al. Surto de antracnose (Colletotrichum guaranicola) do guaranazeiro (Paullinia cupana var. sorbilis) no Estado do Amazonas. Fitopatologia Brasileira, Brasília, v. 27, p. S78, 2002. Suplemento.

ATROCH, A. L. Principais resultados de pesquisa com a avaliação de clones de guaranazeiro no período de 1985 a 1994. In: REUNIÃO TÉCNICA DA CULTURA DO GUARANÁ, 1., 2001, Manaus, AM. Resumos... Manaus: Embrapa Amazônia Ocidental, 2001. 42 p. (Documentos, 16).

ATROCH, A. L.; CRAVO, M. S.; SANTOS, J. A. Enraizamento de clones de guaranazeiro tratados com ácido indol-3-butírico (AIB). In: CONGRESSO BRASILEIRO DE FRUTICULTURA, 17., 2002, Belém. Anais... Belém: Embrapa Amazônia Oriental, 2002. Resumo 025. CD-ROM.

BEZERRA, F. C.; ROSA, M. F. Utilização do pó da casca de coco-verde como substrato para produção de mudas de alface. Fortaleza: Embrapa Agroindústria Tropical, 2002. 4 p. (Documentos, 71).

CARVALHO, J. E. U. et al. Conservação e viabilidade de sementes de guaraná Paullinia cupana var. sorbilis (Mart.) Ducke. Belém: Embrapa-CPATU, 1982. 12 p. (Circular técnica, 35).

CORRÊA, J. C. Limites de consistência dos solos Latossolo amarelo e Podzólico vermelho amarelo na UEPAE de Manaus e sua importância agrícola. Manaus: EmbrapaUEPAE, 1981. 2 p. (Pesquisa em Andamento, 15).

CORRÊA, M. P. F. A pesquisa do guaraná. In: SIMPÓSIO BRASILEIRO DO GUARANÁ, 1., 1983, Manaus. Anais... Manaus: Embrapa-UEPAE, 1984. p. 43-67.
CORRÊA, M. P. F.; STOLBERG, A. G. Z. Propagação vegetativa do guaranazeiro (Paullinia cupana var Sorbilis (Mart. Ducke). Manaus: Embrapa-UEPAE, 1981. 4 p. (Pesquisa em Andamento, 23).

EMPRESA BRASILEIRA DE PESQUISA AGROPECUÁRIA. Manual de métodos de análises de solo. 2. ed. Rio de Janeiro, 1997. 212 p.

EMPRESA BRASILEIRA DE PESQUISA AGROPECUÁRIA. Centro de Pesquisa Agroflorestal da Amazônia Ocidental. Sistema de produção para guaraná. Manaus, 1998. 34 p. (Embrapa-CPAA. Documentos, 13).

FERREIRA, P. V. Estatística experimental aplicada à agronomia. Maceió: Edufal, 1996. 606 p.

INSTITUTO BRASILEIRO DE GEOGRAFIA E ESTATÍSTICA. Sistema IBGE de Recuperação Automática (SIDRA). 2003. Disponível em: 4WWw.ibge.gov.br? Acesso em: 15 dez. 2004.

MOREIRA, A.; MALAVOLTA, E. Variação das propriedades químicas e físicas do solo e na matéria orgânica em agrosistemas da Amazônia Ocidental (Amazonas). Piracicaba: CENA/USP, 2002. 79 p. (Relatório de Pesquisa).

MOURÃO FILHO, F. A. A.; DIAS, C. T. S.; SALIBE, A. A. Efeito da composição do substrato na formação de mudas de laranjeira 'Pêra'. Scientia Agricola, Piracicaba, v. 55, n. 1, p. 35-42, 1998.

SALVADOR, J. O.; MOREIRA, A. Efeito da composição do substrato na formação de mudasode goiabeira. In: CONGRESSO LATINOAMERICANO DE LA CIENCIA DEL SUELO, 14., 1999, Pucon. Resumenes... Temuco: Universidad de La Frontera, 1999. p. 322.

SANTOS, R. R. et al. Desenvolvimento de mudas de maracujazeiro azedo sob diferentes substratos. In: CONGRESSO BRASILEIRO DE FRUTICULTURA, 18., 2004, Florianópolis. Anais... Florianópolis: SBF, 2004. CD-ROM.

SILVA, R. P.; PEIXOTO, J. R.; JUNQUEIRA, N. T. V. Influência de diversos substratos no desenvolvimento de mudas de maracujazeiro azedo (Passiflora edulis Sims f. flavicarpa DEG). Revista Brasileira de Fruticultura, Cruz das Almas, v. 23, n. 2, p. 377-381, 2001. 